\title{
Is it possible to assess the "ethics" of medical school applicants?
}

Michael Lowe, Ian Kerridge, Miles Bore, Don Munro and David Powis Fiji School of Medicine, Fiji, and

University of Newcastle, Australia

\begin{abstract}
Questions surrounding the assessment of medical school applicants' morality are difficult but they are nevertheless important for medical schools to consider. It is probably inappropriate to attempt to assess medical school applicants' ethical knowledge, moral reasoning, or beliefs about ethical issues as these all may be developed during the process of education. Attitudes towards ethical issues and ethical sensitivity, however, might be tested in the context of testing for personality attributes. Before any "ethics" testing is introduced as part of screening for admission to medical school it would require validation. We suggest a number of ways in which this might be achieved. (Fournal of Medical Ethics 2001;27:404-408)

Keywords: Ethics; medical school selection; personality

"A devil, a born devil, on whose nature

Nurture can never stick; on whom my pains,

Humanely taken, all, all lost, quite lost . ..”
\end{abstract}

Shakespeare: The Tempest. Act IV, scene 1 (line 198)

\section{Introduction}

The recent Shipman case in the United Kingdom has drawn attention once again to questions about how the profession reacts to unethical doctors. A spokesman for the British Medical Associaton (BMA) said "Shipman was found guilty, not the medical profession"; but perhaps this lets the medical profession off too lightly. After all, it was the medical profession that allowed his entry to medicine; and it is because he is a member of the profession that he had access to drugs, and access to his patients' trust. It is also the medical profession, which is in part responsible for the lax standards of audit that allowed him to get away with this.

What Dr Shipman did was illegal, but the situation clearly goes beyond legal considerations. When the judge in the case stated: "Finally you have been brought to justice for your wicked, wicked crimes . . ." and the BMA spokesman stated: " . . this is an evil man ...", it was clear that they were referring not just to illegality, but to immorality as well.

It is instructive to try to imagine what went wrong with Dr Shipman, and when this might have happened. Did he become a moral outsider as he progressed through the profession, or was he like that from the beginning? If he changed during his time in the profession, could this have been prevented, or recognised earlier? Could his future have been predicted when he was at medical school and if so, might it have been possible to educate him to prevent his later actions happening?

Given the paucity of evidence that undergraduate or postgraduate education may change or shape ethical practice in the long term, it seems that the only way to prevent people like Dr Shipman from continuing in the profession might lie in attempting to identify unethical doctors prior to entering medical school or during their undergraduate or postgraduate education, and excluding them from the profession before they cause harm.

We have been examining the issue of whether it is possible to use ethics testing as part of the admission criteria for medical students in Australian medical schools. Unsurprisingly, this leads to a number of methodological and philosophical issues that require further exploration. The aim of this paper is to examine these issues in more detail to assess whether there are any compelling reasons why we should not examine the ethics of aspiring medical students.

\section{Ethics}

Ethics is the study of what we ought to do. An unethical doctor is therefore a doctor who does things that he or she ought not, or does not do the things that he or she should.

There are a number of factors that enable doctors to act in an ethical way, including a desire or motivation to do so, a knowledge of ethical issues, the development of communication skills and other skills required for medical competence, a capacity for moral or ethical reasoning (we will use the terms "moral" and "ethical" synonymously), and an individual's beliefs, attitudes, and sensitivity to ethical issues. Educationally, these factors appear to fall into two main groups - those that can be taught, and those that appear to be innate.

If we decide to examine students' ethical backgrounds before they enter medicine, it seems important that we should not examine topics or skills that can be taught; rather we should teach these at some stage during the course. These areas may include an ethical knowledge base, communication skills, and skills required for professional competence. All are extremely important for ethical behaviour, yet would be unnecessary in an ethics entrance exam. 
A different problem occurs with the question as to whether we should examine students' ethical reasoning. In many ways, ethical reasoning is like any other form of reasoning, it is simply the application of logic to matters of morality. Students who are selected for medicine on the basis of other tests of logic, are likely to do well at tests of moral reasoning as well.

However, the term "moral reasoning" also has a slightly different meaning, referring not only to a process of logic, but also to a process of ethical maturation or development, such as in Kohlberg's theory of ethical development. Kohlberg came to the conclusion that moral development occurred in six defined stages, leading from a state of moral immaturity in which ethical decisions were taken ad hoc, to higher levels of moral development which involved individuals acting objectively, rationally, and impartially, following universal ethical principles of a higher morality. His theory has been studied extensively, and it underlies the development of measures of moral reasoning such as the Mora Judgement Interview (MJI), ${ }^{3}$ The Defining Issues Test (DIT) ${ }^{4}$ and the Sociomoral Reflection Measure (SRM).

Kohlberg's theory suggests that as the individual ages, the cognitive ability to reason morally moves through a hierarchy of invariant stages. ${ }^{3}$ Age, however, is not the only variable in moral development, as studies suggest that the opportunity to experience an enriched moral decision making environment may also influence moral reasoning scores. Self, Baldwin, and Wolinsky provided an example of this effect when they demonstrated that medical students had a highly significant gain in the adoption of principled reasoning as measured by the DIT after a course in medical ethics. ${ }^{7}$ This has also been observed in other longitudinal studies, and in a meta-analysis by Schlaefli, Rest, and Thomas. ${ }^{9}$ These findings support the notion that educational experience can increase moral reasoning scores.

However, it is unclear how moral reasoning is related to moral decision making, since tests of moral reasoning tend to be based upon the justifications produced by an individual after a moral decision has been made. Indeed, Kohlberg's theoretical premise in developing his theory of moral reasoning was that reasoning is independent of moral decisions made.

It appears therefore that, since moral reasoning has been shown to change with the educative experience and may be unrelated to the moral decisions individuals make, measures of moral reasoning are unlikely to be suitable for inclusion in the selection of applicants for medical education.

Indeed, if we think once more of Dr Shipman, it seems likely that he had adequate skills in both communication and clinical medicine, that he may have had some knowledge of medical ethics, and that he may have been able to apply logic to moral matters as easily as to other matters in his professional life. Yet none of these attributes prevented him from becoming a murderer.

\section{Ethical beliefs, attitudes and sensitivity}

It would not be technically difficult to examine applicants for particular ethical beliefs, and there are some ethical beliefs that may make medicine difficult to practise in some environments. For example, applicants from some ethnic groups may believe that it is reasonable to perform female circumcisions despite this being widely considered in Western society to be immoral; some applicants may be willing to sabotage animal experiments out of interest for the animals; yet others may believe it is a valuable aim of humanity to pharmacologically enhance sportsmen and women so they can perform better.

However, we do not believe applicants to medical school should be rejected because of their individual ethical beliefs, as ideas can be developed or discarded by individuals throughout their medical training and later careers. Unsophisticated beliefs about ethical subjects should be expected in junior students, and one role of medical education is to broaden their experience and knowledge-base.

It may be possible to test for ethical sensitivity by providing applicants with a vignette and giving them a task to perform, such as coming up with a list of ethical issues that might arise, or justifying the various courses of action. It seems likely, however, that performance of this sort of artificially constructed task is more dependent upon post hoc moral justification than actual sensitivity. Many intelligent students could approach this problem as an exercise in logic or as a type of game and provide satisfactory responses without any recourse to ethics. On the other hand, we do believe that it may be possible to test ethical attitudes and sensitivity to ethical issues by looking at certain personality traits. In 1997, one of the authors (MB) conducted interviews with 32 respondents from the academic and general staff of the University of Newcastle, and medical staff from hospitals in Newcastle, Australia. In each interview the respondents were asked if they had, in their professional experience, observed any students who behaved in a way they believed was ethically inappropriate to the practice of medicine. Respondents were then asked to describe and give instances of the inappropriate behaviours, and to describe any inappropriate attitudes they had observed.

Respondents shared a number of descriptive words for unethical behaviour (see table 1). It can be seen that most respondents appear to be describing character traits that they interpret as being associated with unethical behaviour rather than unethical behaviour itself. (This notion that ethics can be understood in terms of personality goes back to Aristotle and finds contemporary expression in "virtue ethics".)

This picture of unethical doctors-as narcissistic egotists, unconcerned with anyone's interests but their own - is familiar to anyone involved with the medical profession or its representations in the popular press; and these descriptions match the profiles described in some other studies of unethical doctors. For example, in a 1991 review of doctors 
Table 1 Common descriptors by medical professionals of ethically inappropriate medical student behaviours and attitudes

\begin{tabular}{lllll}
\hline Descriptors: & & & & \\
\hline & & & & \\
Arrogant & Brash & Antisocial & Rude & Condescending \\
Power-seeking & Egocentric & Amoral & Aggressive & Rigid attitudes \\
Inflexible & Isolated & Devious & Insensitive & No give and take \\
Defensive & Indifferent & Prejudiced & Self centered & Judgmental \\
Dishonest & Selfish & Flippant & Uncaring & \\
Patronising & & & & \\
\hline
\end{tabular}

convicted of fraud in relation to the USA government insurer, Medicaid, the investigators noted: "None of the physicians took full personal blame for his or her violation of a legitimate law or rule .... At the most, the physicians that we interviewed might acknowledge that they had been a little careless, but this was said to have been because they were fundamentally trusting people, more interested in the welfare of others than their own salvation, and that this character flaw had stood them in ill stead .... The physicians typically saw themselves as sacrificial lambs hung out to dry because of incompetent or backstabbing employees, stupid laws, bureaucratic nonsense, and a host of similar reasons." ${ }^{\prime \prime}$ Such doctors could clearly be described with many of the words used above.

However, there are ways of being unethical other than by being a self-serving egotist. The Nazi doctors, for example, strike one as anything but thistheir crime was to go along too easily with the group, not to stand out from it. This type of personality is sometimes known as the "authoritarian" personality. ${ }^{11}$ Authoritarians unquestioningly abide by the expectations and demands made by those people and institutions they consider to be in authority and may be likely to punish those who do not abide by them, or those who are considered to be inferior to the authority. ${ }^{12}$ An authoritarian doctor may not stand out as a medical student yet it is not difficult to see how authoritarian attitudes can lead to inappropriate behaviour in the practice of medicine.

A third type of unethical doctor may be one who does not care about the ethical side of his practice for other reasons-either because he is unconcerned with the ethical component of life in general, because he is burnt out or depressed, or because his interests lie elsewhere, for instance in his financial affairs, relationships or golf.

\section{Ethics versus psychiatric diagnosis}

We have described a number of personality characteristics that may be associated with unethical behaviour. In the extreme cases, some of these personality traits may even be described as personality disorders, although clearly this does not apply in all cases. For example, the egotistic doctors described by our respondents resemble people with narcissistic personality disorders, and doctors who have no ethical perspective bear resemblance to psychopathic or antisocial personalities. (Interestingly, the authoritarian doctors do not appear to correlate to any personality disorder, perhaps because they avoid antagonising anyone with sufficient power to categorise them!)

Several authors have commented upon the links between the ethical domain ("bad") and the psychiatric domain ("mad"). ${ }^{13}$ Many commentators feel these domains should be kept apart as far as possible, and that psychiatric diagnosis should be kept separate from moral judgments. ${ }^{14}$ Yet psychiatry has always had a tendency to move beyond its brief, and moral judgments and psychiatric diagnoses often appear to overlap, particularly in the area of personality disorders. For example, DSM-IV criteria for antisocial personality disorder include "disregard for, and violation of the rights of others"; and narcissistic personality disorder criteria include lack of empathy and interpersonal exploitativeness-all terms that are as appropriate to discussions of morality as they are to psychiatric diagnoses. Since psychiatry has intruded upon the moral domain (indeed it has probably never left this area), we believe that it is entirely appropriate to use some of the tools of psychiatry to investigate morality. A logical place to start is to screen applicants with standard questionnaires for the diagnosis of personality disorders.

If we are going to test applicants for personality disorders, it is important to realise that most medical school applicants have already been picked on the basis of a high level of academic intelligence. The literature on antisocial personalities and psychopaths emphasises how difficult it is to diagnose this condition as people with these conditions may present with "a normal and even a charming and ingratiating exterior ..... Antisocial personality disorder patients do not tell the truth and cannot be trusted to carry out any task or adhere to any conventional standard of morality." ${ }^{15}$ It seems likely that the task of distinguishing a highly intelligent person like this who wished to become a doctor would be even harder than usual, as such people seem likely to be able to see through most questions aimed at discovering them. It seems unlikely therefore that it will be possible to screen for this type of unethical doctor at admission.

The narcissistic personality on the other hand, appears to be relatively easy to trap in his or her own conceits, and there are a number of instruments used for diagnosing this condition. The difficulty with excluding people with this type of personality is that, although it is widely agreed that they are unpleasant to work with, we are struck by the prevalence of narcissistic traits among leaders of 
the profession. If we reject the narcissists, do we lose valuable future leaders who through their own egotism try new ideas and procedures that others do not dare?

As Millon suggests:

"Given our dominant cultural orientation toward self-enhancement, it is often difficult to determine which self-focused traits indicate a narcissistic disorder and which are merely adaptive styles that fit societal modes. Where to draw the line between self-confidence and healthy self-esteem compared with an artificially inflated and empty sense of selfworth is not always an easy task .... When the disorder is present, we see a persistent insensitivity to others, a general social exploitiveness, and lack of reciprocity in everyday relationships. ${ }^{\prime 16}$

We believe it is this exploitiveness which draws a distinction between the doctor who is egocentric and unpleasant, but not necessarily unethical, and the doctor whose narcissism leads to unethical behaviour. In the narcissistic personality disorder:

“... persons feel entitled, expecting special favors without assuming reciprocal responsibilities. Not only are they unempathic, but they also take others for granted, are shameless in the process, and use others to enhance their own personal desires. Narcissistic individuals seek accomplishments of normal life with minimal effort and reciprocity on their part.”16

\section{Conclusion}

Medical school entry is based upon a number of factors. Cut off marks for academic performance are perhaps the most popular methods of excluding potential applicants, although there is no evidence to justify the extremely high marks required for many courses. Courses are now including tests of logical reasoning, tests of lateral thinking, and testing that is known to discriminate in favour of certain groups (eg women) to the disadvantage of others. Entry testing produces a population that is known to be skewed, and there are notable inequalities in students who are selected that are unjustifiable from an ethical perspective.

As Treanor states:

"The inequalities of access to university (initial selection) are well known. Social class, parents' income, parents' education, geographical access to education and (decreasingly) sex - all these are recognized factors. So is intelligence, but with dispute on its quantification."

And:

“. . . all the evidence is, that the less a group or category is represented in the initial intake, the less chance it has of getting through university. In other words: universities continue to disadvantage the same people who were disadvantaged by the university entrance exams." ${ }^{17}$

We are not aware of any medical schools which test explicitly for moral or ethical attributes of applicants for medicine, although these topics are frequently covered in interviews. The reason for this is probably concerns about the methodological issues involved in defining and testing ethical attributes, and fear of introducing new biases and new forms of unjustified discrimination into the selection process. Indeed, if we are to develop measures for assessing applicants' attitudes and sensitivity to moral issues, it is important that these should not be based purely on theoretical structures, but that they also be validated empirically. The main difficulty with validation is how to define unethical behaviour well enough to test any measures developed. While problematic, the task of validating an ethics test is not entirely insuperable and complementary approaches, such as comparing students' test results with ratings from interview, undergraduate ethics assessment and residency reports may provide a means for test validation.

While the questions surrounding the assessment of applicants' morality are difficult, they are nevertheless important for medical schools to consider. This is an area which is ripe for further research, and we believe we have identified some of the directions in which such research should proceed. The Shipmans of our profession may prove to be identifiable only after evidence of their inappropriate behaviour becomes apparent. It is our conclusion, however, that credible attempts should be made to at least minimise the chances of unethical behaviour occurring. Not to do so would seem to be ethically inappropriate in itself.

Michael Lowe, BMed, FRACP, is Associate Professor in Medicine, Fiji School of Medicine, Lautoka, Fiji. Ian Kerridge, BA, BMed (Hons), MPhil, FRACP, FRCPA, is Director of the Clinical Unit in Ethics and Health Law, Faculty of Medicine $\mathcal{G}$ Health Sciences, University of Newcastle, New South Wales, Australia. Miles Bore, BAPsych (Hons), is a Research Academic in the Department of Psychology, University of Nervcastle, New South Wales Australia. Don Munro, PhD, is Senior Lecturer in the Department of Psychology, University of Newcastle, New South Wales, Australia. David Powis, BSc (Hons), PhD, is Associate Professor of Human Physiology and Chair of the Undergraduate Selection and Admissions Committee in the Faculty of Medicine $\mathbb{E}$ Health Sciences, University of Nervcastle, New South Wales, Australia.

\section{References}

1 Ashraf $\mathrm{H}$. UK general practitioner guilty of killing 15 patients. Lancet 2000;355:471

2 Anonymous [editorial]. Effect of Shipman case on family practice. Lancet 2000;355:422.

3 Kohlberg L. Essays on moral development vol 2: the psychology of moral development. San Francisco: Harper and Row, 1984. 4 Rest JR. Development in judging moral issues. Minneapolis: University of Minnesota Press, 1979.

5 Gibbs JC, Basinger KS, Fuller D. Moral maturity: measuring the development of sociomoral reflection. New Jersey: Lawrence Erlbaum, 1992

6 Crisham P. Measuring moral judgment in nursing dilemmas. Nursing Research 1981;30:104-10.

7 Self DJ, Baldwin DC, Wolinsky FD. Evaluation of teaching 7 Self DJ, Baldwin DC, Wolinsky FD. Evaluation of teaching Education 1992;26:178-84. 
408 Is it possible to assess the "ethics" of medical school applicants?

8 Rest JR, Thomas SJ. Relation of moral judgment development to formal education. Developmental Psychology 1985;21:709 14

9 Schlaefli A, Rest JR, Thomas SJ. Does moral education improve moral judgment? A meta-analysis of intervention studies using the defining issues test. Educational Research 1985;55:319-52.

10 Jesilow P, Geis G, Pontell H. Fraud by physicians against Medicaid. Fournal of the American Medcial Association 1991;266: 3318-22.

11 Adorno TW, Fenkel-Bruswik E, Levinson DJ, Sanford RN. The authoritarian personality. New York: Harper and Row, 1950.

12 Altemeyer B. Enemies of freedom: understanding right-wing Altemeyer B. Enemies of freedom: understanding
authoritarianism. San Francisco: Jossey-Bass, 1988.
13 Prins H. Psychiatry and the concept of evil. British fournal of Psychiatry 1994;165:297-302.

14 Jones G. Comment on 'Psychiatry and the concept of evil'. British fournal of Psychiatry 1994;165:303-4.

15 Kaplan HI, Saddock BJ, Grebb JA. Kaplan and Saddock's synopsis of psychiatry [7th ed]. Baltimore: Williams and Wilkins, 1994: 738 .

16 Millon T. Disorders of narcissism: diagnostic, clinical and empirical interpretations. http://www.npd-central.org/millon.asp accessed $14 / 4 / 2000$

17 Treanor P. Ethics and academic selection. http:// web.inter.nl.net/users/Paul.Treanor/ac.ethics.html accessed 14/4/2000 